\title{
Research on the risk of block chain technology in Internet finance supported by wireless network
}

\author{
Yu Chen ${ }^{1}$, Yayun Zhang ${ }^{2}$ and Bo Zhou ${ }^{1 *}$
}

\begin{abstract}
In this paper, a cascaded depth learning framework is constructed. A cascaded depth model is successfully implemented by studying and analyzing the specific feature transformation, feature selection, and classifier algorithm used in the framework. A feature combination method based on enhanced feature selection and classification is proposed according to the different features learned by each layer of the model. Combining block chain cryptography technology, distributed technology, consensus accounting mechanism of technology innovation, transaction data encapsulation into specific format data unit, encapsulated into a linear list in chronological order, using encryption algorithm trading transparency, traceability of data, security, credibility, and uniqueness in financial data analysis. The experimental results show that with the increase of the number of model layers, our method can significantly improve the classification accuracy. This result also verifies that the proposed model can learn more effective data representation features and also verifies the effectiveness of the proposed feature combination method.
\end{abstract}

Keywords: Block chain, Internet financial risk, Credit risk, Wireless network

\section{Introduction}

In recent years, the hot development of Bitcoin makes the underlying technology block chain gradually become the focus of institutions [1]. Block chain technology reconstructs the credit formation mechanism, and combines with traditional finance, profoundly changing the current business model [2].

Block chain technology integrates cryptography technology, Distributed accounting technology, consensus mechanism, and other technological innovations encapsulates transaction data into a specific format of data units, in time sequence into a linear list, and uses encryption algorithm to achieve transparency, traceability, security, credibility, and uniqueness of transaction data [3-5]. The participants of the block chain technology

\footnotetext{
* Correspondence: y14hu1@163.com

${ }^{1}$ Faculty of Management and Economics, Kunming University of Science and Technology, Kunming 650093, China

Full list of author information is available at the end of the article
}

keep a complete copy of the data independently to ensure the reliable storage of the transaction data [6]. All parties establish coordination, communication, and incentive mechanisms, collectively participate in the accounting and verification of accounting data in the distributed network, and jointly build and maintain a shared distributed database [7].

Block chain finance is essentially the application of block chain technology in the financial field, that is, to reduce system costs and improve service efficiency in the financial business innovation by using safe, flexible, high transparency, and decentralized block chain technology [8].

Block chain finance, which belongs to the concept of self-financing, has the characteristics of optimizing transaction mode, strengthening credit risk control, and reducing the cost of value transfer. Its transaction process can realize the non-destructive transfer of trust [9]. It can be called Renren Finance because individuals 
with cash flow provide financial services directly without the assistance of intermediaries [10]. Therefore, in the block chain financial model based on block chain technology, transaction automatic record verification, realtime updating, information disclosure, has changed the traditional financial transaction mode dependent on intermediaries. At the same time, the unforgettable characteristics of block chain technology are also conducive to inquiring and supervising the flow of funds, strengthening the supervision of credit risk, so as to realize the point-to-point transaction of borrowers [11]. In addition, in the transaction process, block chain finance can effectively reduce the cost of payment, shorten the transaction time, facilitate the interconnection of the global economy, and gradually realize low-cost value transfer [12].

The rest of this paper is organized as follows. Section 2 discusses the proposed algorithm, followed by the block chain financial risk assessment in Section 3. Evaluation system of influencing factors is discussed in Section 4. Section 5 shows ABS mode of Internet consumer finance based on block chain, and Section 6 concludes the paper with summary and future research directions.

\section{The proposed algorithm}

To understand the concept of block chains, we need to define the following concepts: digital signatures involve a hash function, the sender's public key, and the sender's private key. There are two functions of digital signature: (1) to confirm that the message is sent out by the sender's signature and (2) can determine the integrity of messages.

SHA256: a hash function that inputs any string of data to get a 256-bit hash value [13]. The same data input will get the same result. A slight change in the input data yields a very different result, and the result is unpredictable. Forward calculation is very easy. Reverse calculation is extremely difficult. It is regarded as impossible under current scientific and technological conditions [14].
Merkle Tree: a hash two binary tree, which can quickly check the integrity of large-scale data. In the Bitcoin network, the Merkle tree is used to generalize all transaction information in a block and eventually generates a unified hash value of all transaction information in the block. Any change of transaction information in the block will make the Merkle tree change [15]. The hash two-fork tree is shown in Fig. 1.

Any machine can run a complete Bitcoin node, and a complete Bitcoin node includes (1) wallet, allowing users to trade on the block chain network; (2) complete block chain, recording all transaction history. The security of historical transactions is guaranteed through special structures and used to verify the legitimacy of new transactions; (3) Miners, generate new blocks by recording transactions and deciphering math problems. If successful, you can earn rewards; (4) routing function, it is necessary to transfer information from other nodes to more nodes [16]. Figure 2 shows the node network of the block chain.

The transaction process under block chain is shown in Fig. 3.

The transaction process of block chain network can be divided into five steps [7].

Step 1: Owner A uses his private key to sign a data signature for the previous transaction (source of Bitcoin) and next, owner B (address of the recipient with the public key) attaches the signature to the end of the currency to make a transaction order.

Step 2: A broadcasts the transaction order to the whole network, and the Bitcoin is sent to B. Each node incorporates the received transaction information into a block (which can be used only after six blocks have been confirmed).

Step 3: Each node gains the right to create a new block by solving a mathematical puzzle and gains a bit coin reward (new bitcoins are created in the process).

Step 4: When a node finds a solution, it broadcasts all timestamp transactions recorded by the block to

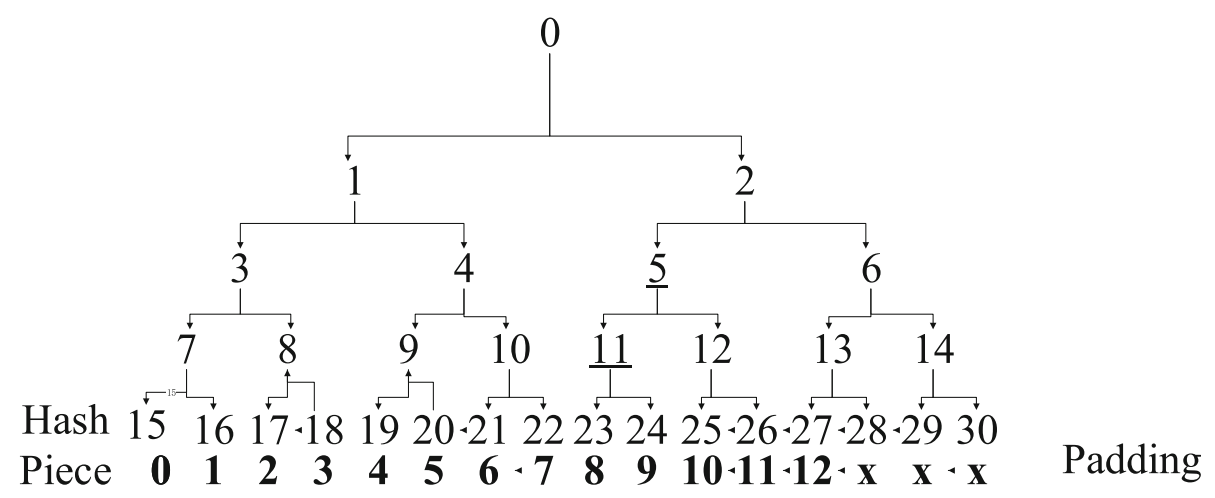

Fig. 1 Cascaded deep learning framework 


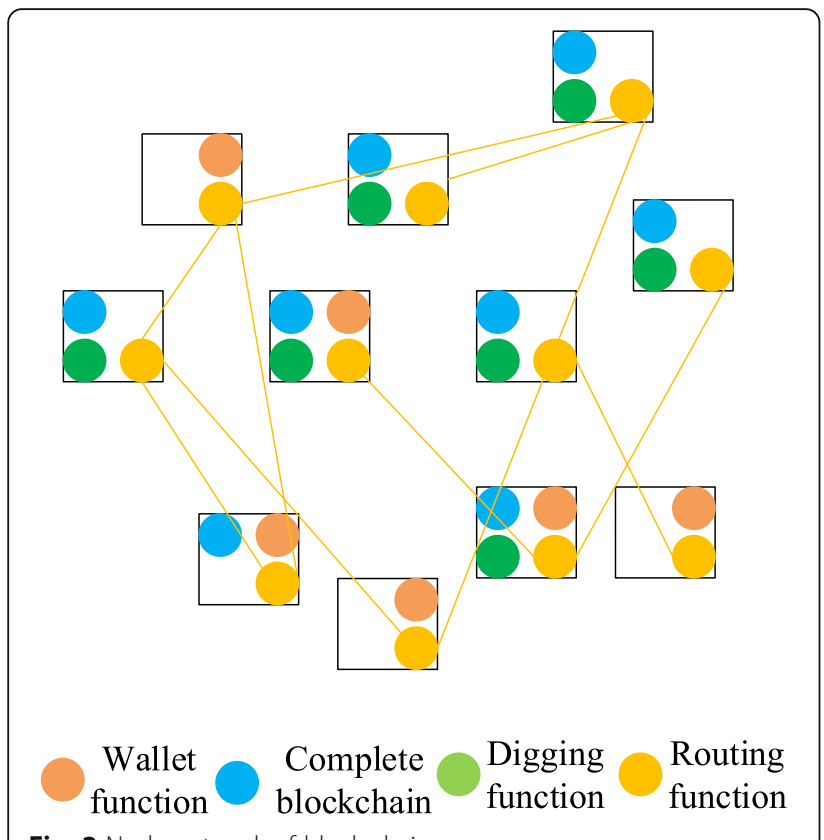

Fig. 2 Node network of block chain

the entire network (taking the median value of five nodes) and checks with other nodes throughout the network.

Step 5: The rest of the network checks the correctness of the block's accounting, and they will compete for the next block after the legitimate block if there is no error. This creates a chain of legally booked blocks (one is generated in about $10 \mathrm{~min}$, automatically adjusting the difficulty based on the last 2016 blocks generated).

\section{Block chain financial risk assessment}

The so-called block chain is actually a block of data generated by a set of encryption methods used to record all the signals that occur on the block, which can record all the transaction information that occurs on the block. Simply put, the block chain can be called an open distributed accounting system running on the network. It is the application of end-toend, point-to-point, P2P Internet finance. A special information in this credit block is the timestamp. For example, Bitcoin block chain, each participant is a node in the block network, and each transaction information is registered on the node, thus forming a public book backup, and each transaction information initiated on the node will be accurately verified and updated [17]. In addition, as the number of transactions increases, different blocks will store different books, and new transaction data will be superimposed on the existing block chains, which will develop into a chain structure over time [7]. The traditional centralized credit model almost requires the use of third-party credit institutions to process payment information trustfully, compared with the block chain network model, which is a distributed database that is almost impossible to change. It maintains a reliable database through decentralization and peer-to-peer approach and has a tremendous impact on innovation in the financial sector, thus developing rapidly worldwide. Figure 4 shows the comparison between the traditional centralization credit mode and the block chain network mode.

Combining with the corresponding credit risk theory, this paper extracts the data of non-performing

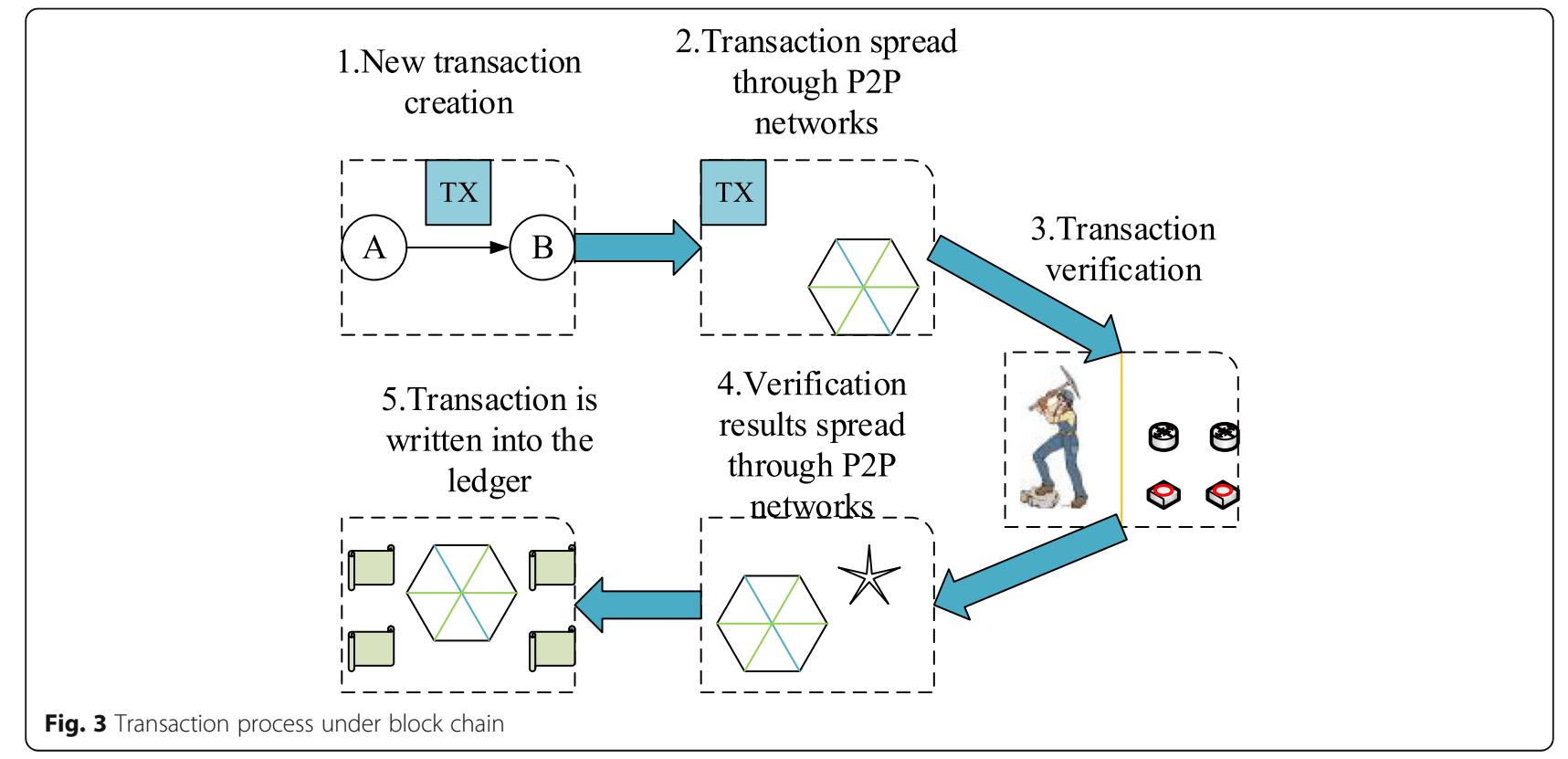




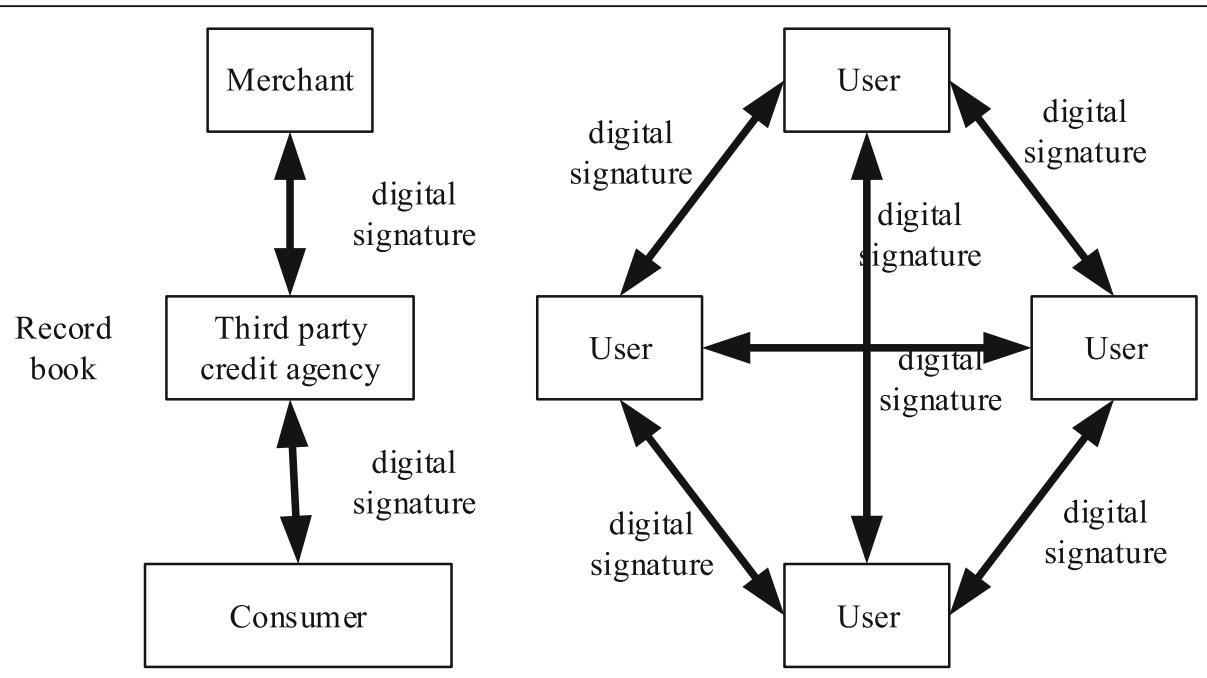

Traditional central credit model

Blockchain credit model

Fig. 4 Comparison between the traditional centralization credit mode and the block chain network mode

loan rate, loan loss preparation, loan-to-asset ratio, deposit-to-asset ratio, and capital adequacy ratio as independent variables. CPI and bank size are used as control variables to remove unrelated variables unrelated to credit risk [18]. Relevant equations are designed. Regression analysis and hypothesis test are used to study the relationship between credit risk and profitability of commercial banks.

In this paper, we use random effect regression model to analyze panel data. Panel data refers to the sample data consisting of multiple cross sections taken from time series and simultaneously selected from the sample observations on these interfaces [19]. Generally speaking, regression analysis is a quantitative statistical method to deal with the relationship between variables. It mainly studies the influence of independent variables on dependent variables. By establishing the regression equation between variables, the change of dependent variable is predicted according to the change of independent variable. Regression analysis extracts the data samples from the article, carries on the statistical test to the data, and finds out which are the significant factors affecting the dependent variable. Then, the influence of independent variable on dependent variable is predicted based on the estimated relational result. The random effects model is a generalization of the classical linear model, which regards the original (fixed) regression coefficient as a random variable, and generally assumes that it comes from normal distribution [20].

According to the above discussion, the models established in this paper are as follows:

$$
\begin{aligned}
& N I M=\alpha-\beta_{1} N P L R_{t s}+\beta_{2} L L R_{t s}+\beta_{3} C C A R_{t s} \\
& +\beta_{4} D A R_{t s}+\beta_{5} L A R_{t s}+\beta_{6} I N F_{t s}+\beta_{7} S I Z E_{t s}+\varepsilon_{t s} \\
& t=2010,2011,2012,2013,2014,2015,2016, s=1,2,3,4
\end{aligned}
$$

According to the collected panel data of listed commercial banks, this paper firstly carries out the fixed effect regression and then carries out the Hausman test according to the obtained parameters. The test results show that the individual effect has nothing to do with the regression variables, so the random effect model is used to regression the sample panel data, and the equation results are as follows[21, 22]:

$$
\begin{aligned}
& N I M=2.851-0.432 N P L R_{t s}+0.099 L L R_{t s}+0.023 C C A R_{t s} \\
& +1.343 D A R_{t s}-0.162 L A R_{t s}-0.0121 I N F_{t s}+0.0001 S I Z E_{t s}+\varepsilon_{t s} \\
& t=2010,2011,2012,2013,2014,2015,2016, s=1,2,3,4
\end{aligned}
$$

We collect the data from the random variable model collation, using the Stata measurement software to make data, and the results are collated as shown in Table 1.

According to the above results, the profitability of commercial banks and macroeconomic factors and the size of commercial banks are related. The higher the CPI index, the worse the profitability. It is presumed that 
Table 1 Stata random effect regression results

\begin{tabular}{|c|c|c|c|}
\hline & $(1)$ & $(2)$ & (3) \\
\hline Variables & NIM & NIM & NIM \\
\hline \multirow[t]{2}{*}{ NPLR } & $-0.406^{* * *}$ & $-0.414^{* * *}$ & $-0.432^{* * *}$ \\
\hline & $(-8.61)$ & $(-8.08)$ & $(-8.25)$ \\
\hline \multirow[t]{2}{*}{ LLR } & $0.122^{* * *}$ & $0.144^{* * *}$ & $0.199^{* * *}$ \\
\hline & $(3.11)$ & $(3.12)$ & $(2.64)$ \\
\hline \multirow[t]{2}{*}{ CCAR } & $0.024^{* *}$ & $0.023^{* *}$ & $0.023^{* *}$ \\
\hline & $(2.34)$ & $(2.06)$ & $(2.07)$ \\
\hline \multirow[t]{2}{*}{ DAR } & $1.187^{* * *}$ & $1.254^{* * *}$ & $1.343^{* * *}$ \\
\hline & $(4.38)$ & $(4.50)$ & $(4.68)$ \\
\hline \multirow[t]{2}{*}{ LAR } & -0.094 & -0.155 & -0.162 \\
\hline & $(-0.37)$ & $(-0.57)$ & $(-0.60)$ \\
\hline \multirow[t]{2}{*}{ CPI } & & & -0.012 \\
\hline & & & $(-1.44)$ \\
\hline \multirow[t]{2}{*}{ Constant } & $1.648^{* * *}$ & $1.632^{* * *}$ & $2.581^{* * *}$ \\
\hline & $(5.92)$ & (5.88) & $(3.24)$ \\
\hline Observations & 298 & 298 & 298 \\
\hline Number of bank & 18 & 18 & 18 \\
\hline Significant level & ${ }^{*} p<0.1$ & ${ }^{* *} p<0.05$ & ${ }^{* * *} p<0.01$ \\
\hline
\end{tabular}

the improvement of macroeconomy will lead to the increase of manpower and operating costs of commercial banks, resulting in the weakening of their profitability. The larger the asset scale, the stronger the ability to resist risks.

\section{Evaluation system of influencing factors}

In order to quantitatively evaluate the risk of block chain finance, a risk assessment system is constructed. Firstly, the first-level evaluation index system is established, and then the corresponding second-level indicators are established according to the status quo of block chain finance. Secondly, the second-level indicators are scored, and the weights of the second-level indicators are summed up as the first-level indicators to measure the financial risk of the block chain, so as to complete the risk assessment.

Selecting scientific research institutions and financial science and technology enterprises to conduct a questionnaire survey, field visits, and the issuance of paper questionnaires to collect the original data. After analyzing the questionnaires of 25 experts, the relative importance of each expert to all the primary indicators and secondary indicators can be obtained. Because of the differences between the views of 25 experts, according to the majority principle and combined with the understanding of block chain finance, the data needed for fuzzy judgment matrix are obtained. Based on the analysis of the above questionnaires and the opinions of the above 25 experts, and according to the majority principle, all the judgment matrices A of the primary and secondary indicators are constructed, as shown in Table 2.

$$
\begin{gathered}
A_{1}=\left[\begin{array}{ccc}
1 & 3 & 6 \\
1 / 3 & 1 & 4 \\
1 / 6 & 1 / 4 & 1
\end{array}\right], A_{2}=\left[\begin{array}{ccc}
1 & 3 & 1 / 5 \\
1 / 3 & 1 & 1 / 7 \\
5 & 7 & 1
\end{array}\right] \\
A_{3}=\left[\begin{array}{cc}
1 & 1 / 3 \\
3 & 1
\end{array}\right], A_{4}=\left[\begin{array}{ccc}
1 & 1 & 2 \\
1 & 1 & 2 \\
1 / 2 & 1 / 2 & 1
\end{array}\right], A_{5}=\left[\begin{array}{cc}
1 & 1 / 2 \\
2 & 1
\end{array}\right]
\end{gathered}
$$

According to the calculation formula, the eigenvector corresponding to each maximum eigenvalue can be obtained. The square of each element of the eigenvector represents the weight of the corresponding risk factors, so as to obtain the relative importance of the risk factors and judge their impact degree. As shown in Table 3, the table is the result of the calculation of 6 matrices.

It is obvious that technical risk and its impact are the most important. Secondly, the weight of policy and legal risk is $1 / 4$. And the risk of operational risk, credit risk, and liquidity risk is significantly smaller. Combined with the risk questionnaire of 25 experts, the score of single risk factor is evaluated. The results are shown in Table 4.

The evaluation results in Table 4 reflect the weights and proportions of the experts in assessing the high, medium, and low financial risk factors in each block chain. It can be seen that in the evaluation results of the lagging risk of legal policy, the high proportion is 0.8 , indicating that $80 \%$ of experts believe that the risk is high. The main factor fuzzy matrix of the secondary index can be obtained from the result of the single factor evaluation, and the primary factor evaluation matrix of the primary index can be obtained.

Table 2 Primary indicator matrix

\begin{tabular}{llllll}
\hline P & $\mathrm{P} 1$ & $\mathrm{P} 2$ & $\mathrm{P} 3$ & $\mathrm{P} 4$ & $\mathrm{P} 5$ \\
\hline $\mathrm{P} 1$ & 1 & $1 / 6$ & 4 & 3 & 2 \\
$\mathrm{P} 2$ & 6 & 1 & 8 & 7 & 5 \\
$\mathrm{P3}$ & $1 / 4$ & $1 / 8$ & 1 & $1 / 3$ & $1 / 2$ \\
P4 & $1 / 3$ & $1 / 7$ & 3 & 1 & 2 \\
P5 & $1 / 2$ & $1 / 5$ & 2 & $1 / 2$ & 1 \\
\hline
\end{tabular}

Based on the results of the questionnaire, 5 judgment matrices of two level indicators were constructed $(i=1-5)$ 
Table 3 Matrix calculation result

\begin{tabular}{llll}
\hline Matrix & Maximum eigenvalue & CR & The square of the corresponding feature vector \\
\hline $\mathrm{A}$ & 5.280 & 0.063 & $0.277^{2}, 0.936^{2}, 0.071^{2}, 0.163^{2}, 0.128^{2}$ \\
$\mathrm{~A}_{1}$ & 3.050 & 0.048 & $0.915^{2}, 0.384^{2}, 0.121^{2}$ \\
$\mathrm{~A}_{2}$ & 3.060 & 0.058 & $0.248^{2}, 0.107^{2}, 0.963^{2}$ \\
$\mathrm{~A}_{3}$ & 2 & 0 & $0.316^{2}, 0.949^{2}$ \\
$\mathrm{~A}_{4}$ & 3 & 0 & $0.667^{2}, 0.667^{2}, 0.333^{2}$ \\
$\mathrm{~A}_{5}$ & 2 & 0 & $0.447^{2}, 0.894^{2}$ \\
\hline
\end{tabular}

$$
R=\left[\begin{array}{lll}
0.788 & 0.204 & 0.009 \\
0.837 & 0.157 & 0.006 \\
0.330 & 0.150 & 0.520 \\
0.278 & 0.311 & 0.411 \\
0.060 & 0.580 & 0.360
\end{array}\right]
$$

The above $\mathrm{R}$ matrix reflects the evaluation score of the 5 first level indicators. The score of policy and legal risk is high, and $78.8 \%$ of experts believe that the risk is high. For technical risk, the expert score is more concentrated, and $83.7 \%$ of the experts believe that the risk is high and low-risk score is only $0.6 \%$. For operational risk, most experts believe that the risk is low, with only $33 \%$ of the experts scoring highly. There was no significant difference in credit risk scores, and $27.78 \%$ of the experts scored high, $31.1 \%$ of the experts scored low, and $41.1 \%$ of the experts scored low. Finally, liquidity risk was considered high by only $6 \%$ of the experts, while other experts thought it was moderate and low. The above five first-class risk indicators are helpful for us to get the assessment of the financial risk situation of the block chain. Through the primary factor evaluation score matrix $\mathrm{R}$ and the primary index vector $\mathrm{A} 2$, the calculation shows that $B=\mathrm{A} 2 * \mathrm{R}, B=$ $(0.803,0.172,0.025)$. At this point, we completed all block chain financial risk assessment procedures. The final result $\mathrm{B}$ of fuzzy analytic hierarchy process shows that the maximum value of 0.803 is the current evaluation level of the block chain financial risk, that is, the block chain financial risk is in a "high" situation.

According to the relative weight of the first-level indicators, $87.57 \%$ of the technical risk has become the main risk of the current block chain finance, so we should take targeted measures against technology and do a good job in preventing the technical risk of the block chain, in order to promote the development of the block chain finance in a better direction. Secondly, the policy and legal risks, which shows that the relevant policies and regulations are also one of the important risks of block chain finance, we must promulgate the relevant policies and regulations on block chain finance as soon as possible, and implement policies quickly, so that financial institutions have laws to follow. Then, credit risk, there are still

Table 4 Univariate evaluation result

\begin{tabular}{|c|c|c|c|c|}
\hline \multirow{2}{*}{$\begin{array}{l}\text { Primary weight } \\
\text { indicator }\end{array}$} & \multirow[t]{2}{*}{ Secondary weight indicator } & \multicolumn{3}{|c|}{ Evaluation results } \\
\hline & & $\mathrm{H}$ & M & L \\
\hline \multirow[t]{3}{*}{ Policy and law $\left(0.277^{2}\right)$} & Legal policy lag risk $\left(0.915^{2}\right)$ & 0.80 & 0.20 & 0 \\
\hline & Compliance risk $\left(0.121^{2}\right)$ & 0.75 & 0.2 & 0.05 \\
\hline & Regulatory enforcement risk $\left(0.248^{2}\right)$ & 0.45 & 0.45 & 0.10 \\
\hline \multirow[t]{3}{*}{ Technical risk $\left(0.936^{2}\right)$} & Block chain technology risk $\left(0.107^{2}\right)$ & 0.70 & 0.25 & 0.05 \\
\hline & Supporting infrastructure risks $\left(0.963^{2}\right)$ & 0.50 & 0.25 & 0.25 \\
\hline & Cyber-attack risk $\left(0.316^{2}\right)$ & 0.85 & 0.15 & 0 \\
\hline \multirow[t]{2}{*}{ Operational risk $\left(0.071^{2}\right)$} & Personnel operation risk $\left(0.667^{2}\right)$ & 0.15 & 0.15 & 0.70 \\
\hline & Internal supervision risk $\left(0.949^{2}\right)$ & 0.35 & 0.15 & 0.50 \\
\hline \multirow[t]{3}{*}{ Credit risk $\left(0.163^{2}\right)$} & Fraud default risk $\left(0.667^{2}\right)$ & 0.50 & 0.10 & 0.40 \\
\hline & Liquidation lag risk $\left(0.667^{2}\right)$ & 0.10 & 0.50 & 0.40 \\
\hline & Credit scoring system risk $\left(0.333^{2}\right)$ & 0.10 & 0.40 & 0.50 \\
\hline \multirow[t]{2}{*}{ Liquidity risk $\left(0.128^{2}\right)$} & Liquidity plan risk $\left(0.447^{2}\right)$ & 0.10 & 0.50 & 0.40 \\
\hline & Holder run risk $\left(0.894^{2}\right)$ & 0.05 & 0.60 & 0.35 \\
\hline
\end{tabular}


some fraudulent default risk in the financial field and the liquidation lag risk of financial institutions, but compared with the traditional financial risk, risk factors have been greatly reduced, which is determined by the characteristics of block chain technology itself. Finally, liquidity risk and operational risk account for the lowest proportion, because of the rapid economic development, the liquidity plan of financial institutions is relatively perfect, and few people will run maliciously. And because of the development of technology, the number of operator errors is less and less, and the internal supervision and balance mechanism are more and more perfect, so the risk is smaller. The conclusion obtained by fuzzy AHP matches the dual attributes of block chain finance. The two level indicators are analyzed. Among the policy and legal risks, the policy lag risk is the most important, the compliance risk is the second, and the regulatory implementation risk is the least. Block chain finance, as a new form of business, develops rapidly, and the relevant laws and regulations are relatively slow to update, so it cannot play a restraining role on the relevant financial institutions, and financial institutions cannot be relied on because the financial structure is chaotic. Among the technical risks, the network attack risk is the greatest, and the technical risk of the block chain itself and the supporting infrastructure risk are small. Block chain technology is based on the Internet, in recent years, a variety of network viruses or network attacks on the Internet have more and more cases, resulting in huge losses. The block chain technology attacks $51 \%$ of its own POW consensus mechanism, which is difficult to succeed, and its asymmetric encryption mechanism is also difficult to crack, so its technical risk is small.

In operational risk, the risk of internal supervision is the highest, and the risk of personnel operation is small. Block chain technology can dramatically reduce manual intervention and use smart contracts to digitize programs previously heavily dependent on paperwork, which will reduce manual risk and improve efficiency. Compared with the operational risk of personnel, the power constraints of corporate management are not clear. Some managers take advantage of system vulnerabilities and intentionally steal important information, resulting in greater losses to financial institutions.

In credit risk, the risk of fraudulent default is as important as the risk of delayed liquidation of financial institutions. The credit scoring system of financial institutions is constantly improving, so the risk of credit scoring system is smaller. Under block chain finance, we still cannot stop the falseness of original data. Illegal elements falsify personal information, deliberately borrow non-repayment, and deceive financial institutions. At the same time, it takes a certain amount of time for financial institutions to settle bad debts, and it is difficult to sell the corresponding collateral to withstand the loan before, resulting in huge losses.

In the liquidity risk, the holder run risk is bigger, about twice the liquidity plan risk, because the rapid economic development and financial institutions are more mature, liquidity plan is more and more perfect, and the risk is smaller. But if someone maliciously manipulated the market and deliberately ran cash, it would cause serious consequences.

\section{ABS mode of Internet consumer finance based on block chain}

At present, there are many literatures on the mode, risk, and pricing of Internet consumer financial asset securitization at home and abroad, but few researches on the application of block chain in Internet consumer financial asset securitization. Only a few literatures have analyzed the application advantages of block chain in asset securitization, especially the combination of block chain and consumer financial asset securitization. Based on the block chain technology, this paper analyzes the current situation and existing problems of Internet consumer financial asset securitization, expounds that block chain technology can build mutual trust mechanism in the Internet consumer financial asset securitization trading mode, and establish the Internet consumer financial asset securitization trading mode under the block chain. The traditional trading structure of Internet consumer financial assets is shown in Fig. 5.

Its contents are mainly composed of two parts.

Firstly, the subscriber entrusts the subscribed funds to the plan manager through the subscription agreement signed with the plan manager, and the plan manager establishes and manages the special plan. Subscribers acquire asset-backed securities and become holders of asset-backed securities.

Secondly, according to the agreement of the Agreement on the Sale and Purchase of Assets signed with the original equity holders, the special planning funds are used to purchase the basic assets that meet the qualified standards from the original equity holders, that is, the creditor's rights of accounts receivable enjoyed by the original equity holders for factoring business. Third, asset service institutions are responsible for the management of basic assets in accordance with the provisions of the service agreement. It includes, but is not limited to, reports on basic assets services, collection of debtors' repayments, disposal of defaulted basic assets, and rolling investment of follow-up assets packages with pre-recovery of basic assets. Fourthly, the plan trustee manages the special plan account, executes the transfer instructions of the plan manager, and handles 


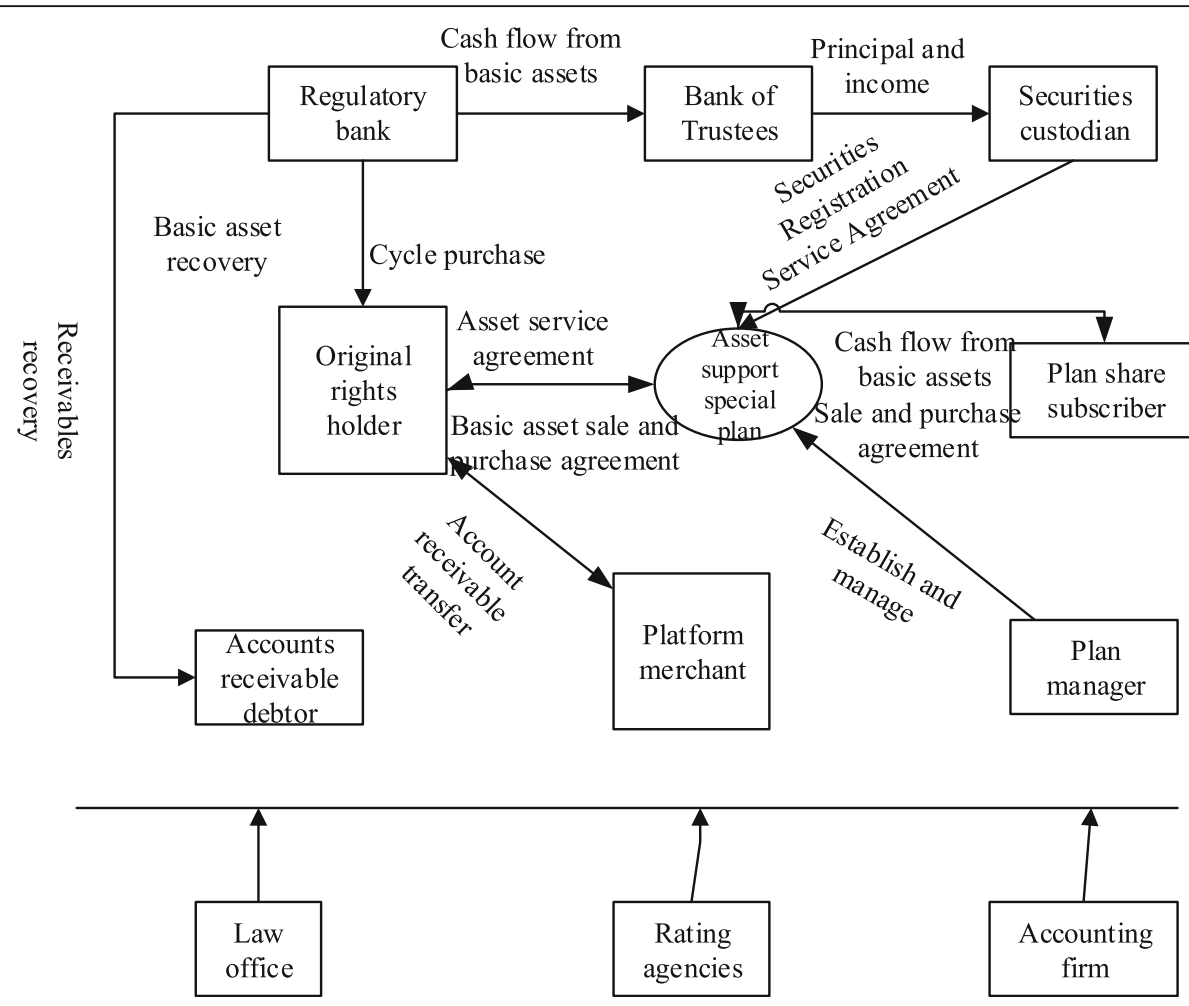

Fig. 5 Traditional trading structure of Internet consumer financial assets

the fund exchange of the special plan according to the agreement of the Trusteeship Agreement.

First, the problem of asymmetric information is serious. Asset securitization involves many subjects, and it is easy to cause information asymmetry among original equity holders, banks, credit rating agencies, SPV, and other subjects, thus causing moral hazard. In addition, banks are very fond of using asset securitization as an off-balance sheet financing model to reduce the financial pressure, so it is easy to ignore the problem of information asymmetry in the credit review, increase lending, thus increasing the risk of Internet consumer financial asset securitization. In addition, the majority of investors in asset securitization business often rely on the results of rating agencies, and rating agencies also serve investors and issuers, all sides of the information gap, so it is very easy to cause moral hazard.

Second, lack of credit mechanism. Compared with ordinary securities, asset-backed securities have the characteristics of longer credit chain, more complex structure, and more serious credit risk. At present, the common problem facing domestic asset securitization is that China's credit system has not been fully formed, and it is impossible to understand the quality, characteristics, and historical credit records of Internet consumer financial debtors. At present, the models used by asset-backed securitization product rating agencies under the background of Internet finance are not perfect, historical credit data accumulation is limited, the term is too short, and there are many products that only rely on the fundamentals of rating. Take the Jingdong Baitiao ABS plan as an example. Although the Jingdong Group has the bottom line and the default rate is very low, the credit data of the consumer financial debtors and the original equity holders may indirectly affect the returns of the holders of asset securitization products.

Third, data processing is difficult. Internet consumer finance is growing in size, and because consumer assets are small and scattered, an institution can trade tens of thousands of transactions, while an ABS product has nearly a million data. The backward data docking mode has increased the difficulty of data acquisition and data processing. In addition, there are many trading systems docking between the main bodies, resulting in more problems such as fund clearing and reconciliation, thus occupying a large number of resources. For example, as of June 2016, Deutsche Bond spent an average of $\$ 1981.02$ on its asset-backed securitization pool of 16.0908 million on its instalment receivables. Such a huge amount of data in the original stakeholders, 


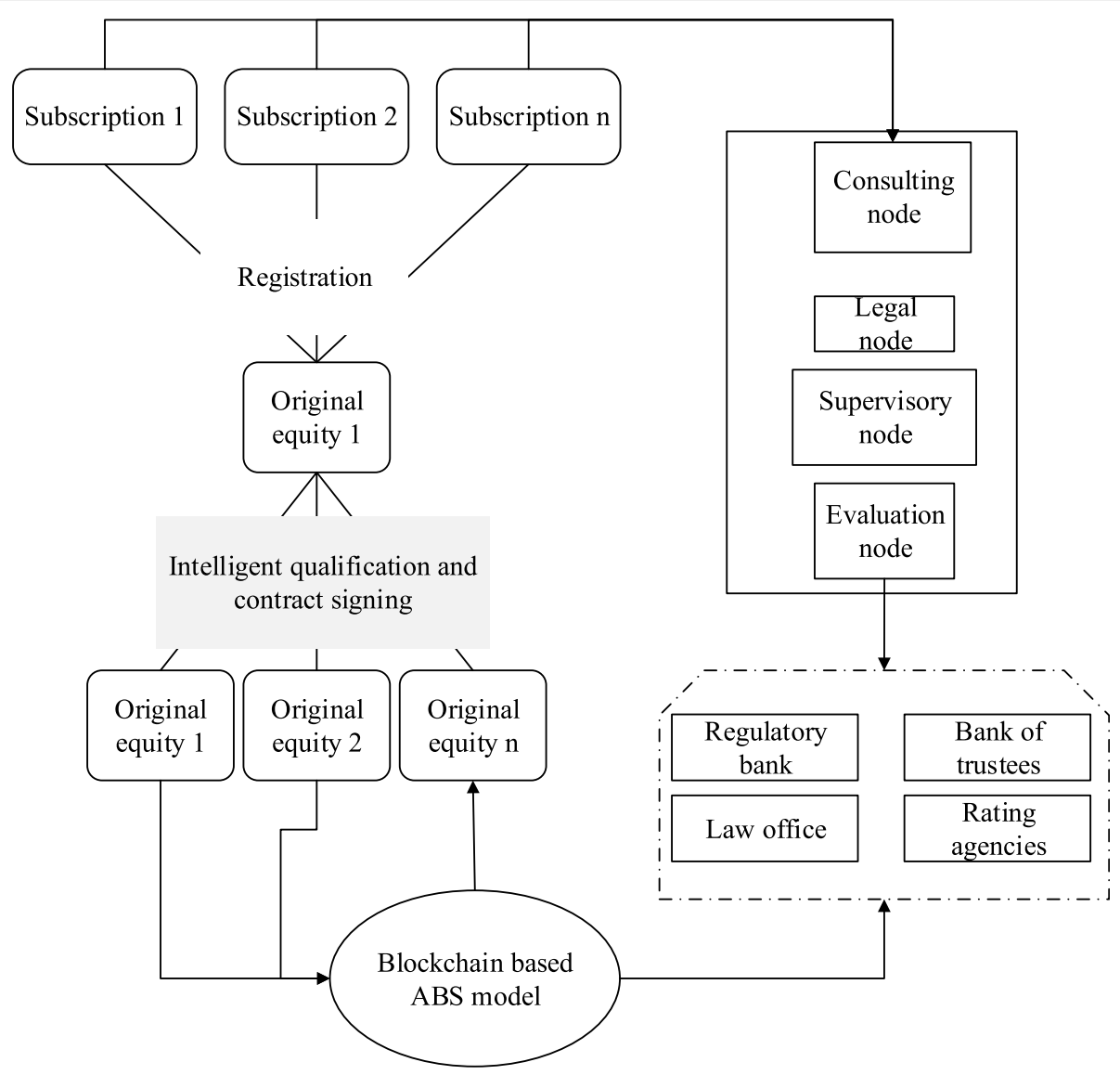

Fig. 6 Block chain-based Internet consumer financial asset

program managers, rating agencies, and other participants between the flow will inevitably cause a large amount of cost loss.

Most of the current financial activities are based on the "centralized" financial media, trading media, and will often worry about financial transactions credit risk. Based on block chain technology and concepts, this paper designs a transaction model by using the characteristics of block chain, such as "unauthorized and decentralized", so as to reduce the participation of intermediaries and reduce credit risk in the whole process of Internet consumer financial asset

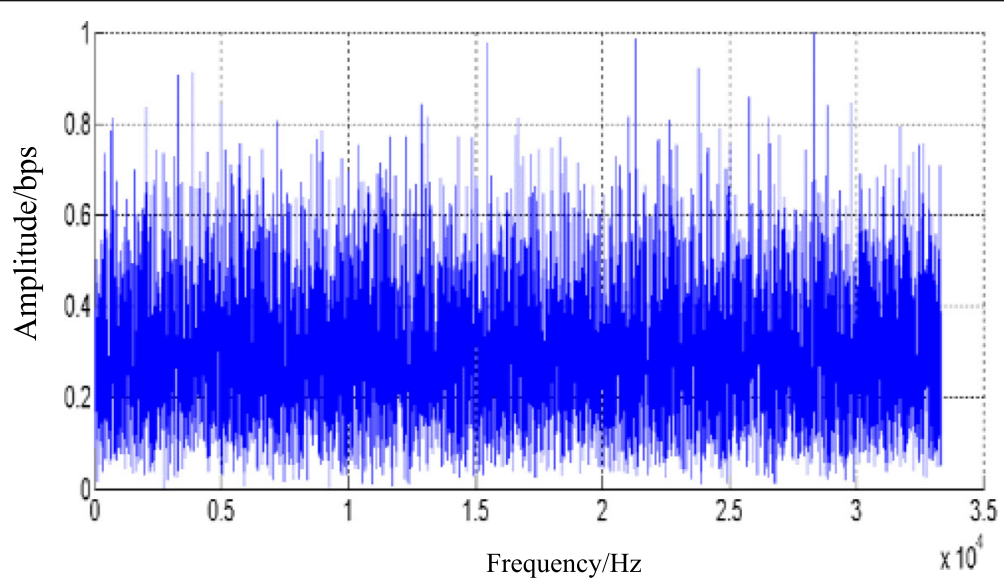

Fig. 7 Time domain waveform of social network protection data 
securitization. Block chain-based Internet consumer financial asset securitization model can be divided into three layers and the lowest layer is the block chain network, which consists of exchanges or trading platform network, forming a decentralized distributed general ledger. The middle layer is the combination of business logic and block chain and jointly establishes the main functions of account center, asset registration, credit evaluation, and network payment, such as consulting, legal affairs, supervision, and evaluation nodes in Fig. 6. The top-level business for the customer can complete the securities trading business, as shown in Fig. 6, and the operation of the asset support project on the left.

Each node in the block chain can verify the integrity and authenticity of the account book to ensure the correctness and security of the transaction information. Because each node in the chain keeps the transaction information, when the information on some nodes is maliciously modified, other nodes in the block chain will find these "different" information in a short time and automatically maintain and update the data. If we must modify the transaction information on the block chain, we must grasp more than $51 \%$ of the computing power of the whole network. Even if the modification is successful, it will inevitably result in a bad situation that the cost of modification far exceeds the expected benefits.

In order to test the application performance of the algorithm in the realization of data protection encryption in social network, the simulation experiment is carried out, and the software design of encryption algorithm is realized by mathematical programming with Matlab 7, and the JobTracker node of privacy protection data in social network is designed. Configured as dual core AMDs, the number of bits of plaintext attack is 1024 bits, the test input data is 10 gigabytes of plaintext encryption block sequences, the encryption rate of privacy protection data in social network is assumed to be 10 , the key parameter is $p k:\{r=7, p=17, q=13, n=p \times q=221, b=6\}$ and $s k$ : $\left\{k_{A}=11, k_{B}=3\right\}$, and the data cross distribution is obtained. According to the above simulation environment and parameter setting, the privacy data of social network are protected and encrypted. The time domain waveform of the data to be protected is shown in Fig. 7.

Taking the data of Fig. 7 as the research object, the data is encrypted to realize the digital protection of social network, and the output of data encryption is shown in Fig. 8.

The performance of data encryption is tested and contrasted with different methods. The comparison results are shown in Fig. 9. It is clearly evident from

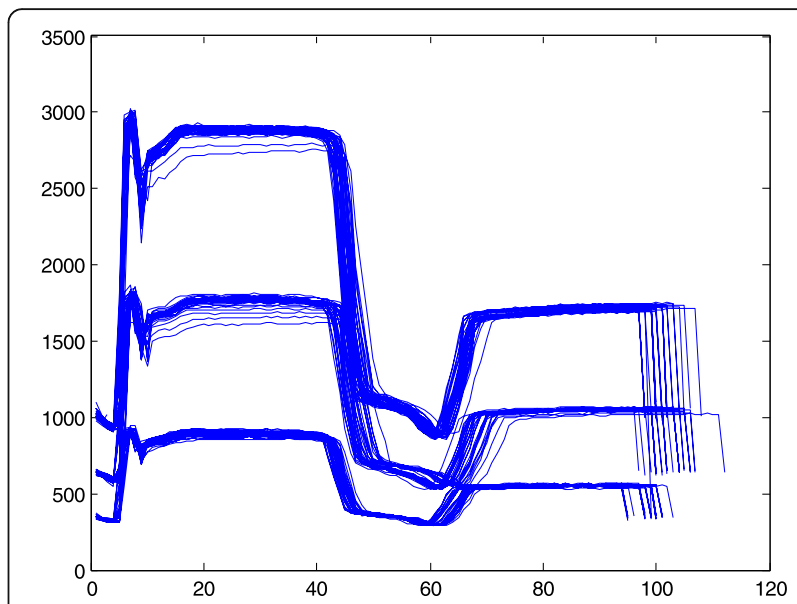

Fig. 8 Data encrypted output

Fig. 9 that the encryption performance of data protection in social network is better by using this method. It plays a good role in promoting the prevention of block chain finance.

\section{Conclusion}

As a financial innovation, block chain technology and traditional securities intermediaries should not be antagonistic, but complementary. Only by promoting and complementing each other can they serve the real economy and stabilize the good order of the financial market. As mentioned earlier, although the Internet consumer financial asset securitization model under the block chain will affect the efficiency of traditional securities, but in terms of management, securities companies still need to perform management responsibilities. Therefore, mutual promotion and supplement can enhance the integrity and transparency of the securities market. Block chain technology enables point-to-point transactions between customers, reduces the cost of intermediary brokerage business, and

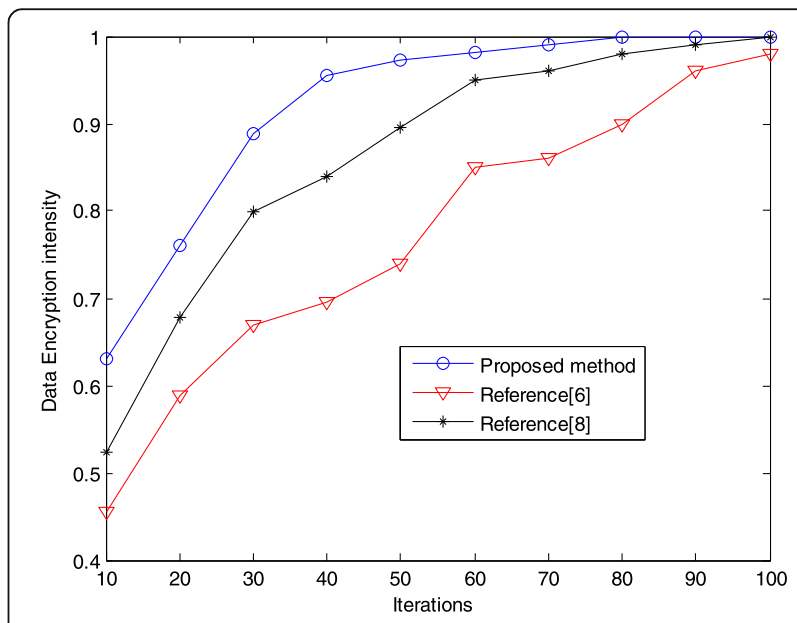

Fig. 9 The consumption power of different models is compared 
strengthens the liquidity of the Internet consumer financial asset securitization market. However, the matching of intermediary agents is still indispensable in docking investment and financing sides and reducing the search cost. Especially, some inexperienced market participants need intermediary services, which can avoid credit and operational risks to a certain extent. Therefore, block chain technology and traditional securities intermediaries still need to complement each other to meet the needs of participants and the market.

\section{Abbreviations}

P2P: Peer to peer

\section{Acknowledgements}

$\mathrm{NO}$

\section{Authors' contributions}

YC was responsible for the writing of the article, YZ was responsible for the data processing of the experiment, and BZ was responsible for the analysis of the experimental results. The authors read and approved the final manuscript.

\section{Authors' information}

About the Authors

Yu Chen received the B.Eng. degree in communication engineering from Kunming University of Science and Technology, China, in 2013, and now is a doctoral candidate in management science and engineering of Faculty of Management and Economics, Kunming University of Science and Technology. His current research interests focus on educational economic management and innovative entrepreneurship education.

Yayun Zhang received the master degree in software engineering from Yunnan University, China, in 2013, and now she is working for Yunnan Open University as a lecturer. Her current research interests focus on intelligent algorithm.

Bo Zhou is a doctoral candidate in financial engineering of Kunming University of Science and Technology. His current research interests focus on financial risks.

\section{Funding}

NO

\section{Availability of data and materials}

The datasets used and/or analyzed during the current study are available from the corresponding author on reasonable request.

\section{Ethics approval and consent to participate}

This article does not contain any studies with human participants or animals performed by any of the authors.

\section{Consent for publication}

All authors agree to submit this version and claim that no part of this manuscript has been published or submitted elsewhere.

\section{Competing interests}

The authors declare that they have no competing interests.

\section{Author details}

'Faculty of Management and Economics, Kunming University of Science and Technology, Kunming 650093, China. ${ }^{2}$ School of computer science, Yunnan Open University, Kunming 650093, China.

Received: 21 November 2019 Accepted: 6 March 2020

Published online: 30 March 2020

\section{References}

1. X. Liu, D. Peng, Y. Wen, Analysis of R \& D Capability of China's Blockchain Technologies. Theoretical Economics Letters 8(10), 1889 (2018)
2. W. Zhang, T. Daim, Q. Zhang, Understanding the disruptive business model innovation of E-business microcredit: a comparative case study in China. Tech. Anal. Strat. Manag. 30(7), 765-777 (2018)

3. Pilkington M. 11 Blockchain technology: principles and applications. Research handbook on digital transformations,: 225.2016

4. J.J. Sikorski, J. Haughton, M. Kraft, Blockchain technology in the chemical industry: machine-to-machine electricity market. Appl. Energy 195, 234-246 (2017)

5. H.I. Ozercan, A.M. Ileri, E. Ayday, et al., Realizing the potential of blockchain technologies in genomics. Genome Res. 28(9), 1255-1263 (2018)

6. K. Christidis, M. Devetsikiotis, Blockchains and smart contracts for the internet of things. leee Access 4, 2292-2303 (2016)

7. M. lansiti, K.R. Lakhani, The truth about blockchain. Harv. Bus. Rev. 95(1), 118-127 (2017)

8. A. Deng, Z. Chen, Managing online supply chain finance credit risk of "Asymmetric Information". World Journal of Research and Review 4, 29-32 (2017)

9. Zheng Z, Xie S, Dai H N, et al. Blockchain challenges and opportunities: a survey. Work Pap.-2016, 2016.

10. M. Crosby, P. Pattanayak, S. Verma, et al., Blockchain technology: beyond bitcoin. Applied Innovation 2, 6-10 (2016)

11. X. Wei, L. Jing, Implementation of personal information security protection technology based on block chain (2018)

12. S.A. Abeyratne, R.P. Monfared, Blockchain ready manufacturing supply chain using distributed ledger (2016)

13. M. Hayashi, T. Tsurumaru, More efficient privacy amplification with less random seeds via dual universal hash function. IEEE Trans. Inf. Theory 62(4), 2213-2232 (2016)

14. K.W. Choi, D.T. Wiriaatmadja, E. Hossain, Discovering mobile applications in cellular device-to-device communications: Hash function and bloom filterbased approach. IEEE Trans. Mob. Comput. 15(2), 336-349 (2016)

15. B. Hu, H. Gharavi, Smart grid mesh network security using dynamic key distribution with merkle tree 4-way handshaking. IEEE Transactions on Smart Grid 5(2), 550-558 (2014)

16. J.E. Pazmiño, C.K.S. Rodriques, Simply dividing a Bitcoin network node may reduce transaction verification time. The SIJ Transactions on Computer Networks \& Communication Engineering (CNCE) 3(2), 17-21 (2015)

17. Belle I. The architecture, engineering and construction industry and blockchain technology. Digital Culture, 279-284.2017

18. L. Baselga-Pascual, A. Trujillo-Ponce, C. Cardone-Riportella, Factors influencing bank risk in Europe: Evidence from the financial crisis. The North American Journal of Economics and Finance 34, 138-166 (2015)

19. A. Kuznetsova, P.B. Brockhoff, R.H.B. Christensen, ImerTest package: tests in linear mixed effects models. J. Stat. Softw. 82, 13 (2017)

20. Z. Huang, X. Xu, J. Ni, H. Zhu, C. Wang, Multimodal Representation Learning for Recommendation in Internet of Things. IEEE Internet Things J. (2019). https://doi.org/10.1109/JIOT.2019.2940709

21. Z. Chen, H. Cai, Y. Zhang, C. Wu, M. Mu, Z. Li, M.A. Sotelo, A novel sparse representation model for pedestrian abnormal trajectory understanding. Expert Syst. Appl. 138, 112753 (2019)

22. L. Dong, Q. Guo, W. Wu, Speech corpora subset selection based on timecontinuous utterances features. J. Comb. Optim. 37(4), 1237-1248 (2019)

\section{Publisher's Note}

Springer Nature remains neutral with regard to jurisdictional claims in published maps and institutional affiliations. 